\title{
FUTURE EXTREME WAVES AT THE GERMAN BALTIC SEA COAST DERIVED FROM REGIONAL CLIMATE MODEL RUNS
}

\author{
Schlamkow C. ${ }^{1}$, Dreier N. ${ }^{1}$, Fröhle P. ${ }^{2}$ and Salecker D. ${ }^{2}$ \\ Information about possible changes of extreme wave heights are essential for the future safe design of coastal and \\ flood protection structures likes dykes, flood protection dunes, revetments etc. In this study, scenarios of regional \\ climate change up to 2100 are used for the evaluation of changes of wave conditions. Analyses on calculated \\ significant wave heights derived from extreme value statistics are showing a different signal of change for the selected \\ locations along the German Baltic Sea Coast. The results are showing that extreme wave heights with a return level of \\ 200 years can increase up to $+14 \%$. But also a decrease of down to $-14 \%$ were found compared to actual conditions, \\ depending on the location and climate change scenario applied. At the location of Warnemünde a slight increasing \\ trend for the change of extreme wave heights could be found for 3 of 4 scenario runs with a maximum increase of \\ $+7 \%$. \\ Keywords: Baltic Sea; Climate Change; Extreme Waves; Cosmo-CLM
}

\section{INTRODUCTION}

Significant changes of mean wind conditions and directions due to climate change can have important consequences for the average wave conditions and other coastal related processes like e.g. the change of the long-shore sediment transport (Dreier et al. 2012). The changes of the sediment transport characteristics may also have effects on the functional design of coastal protection structures at sandy coasts like e.g. beach nourishments and groins.

In addition to the analyses on the change of average wave conditions also possible changes of extreme wave events have to be investigated. The determination of extreme wave heights as a design parameter for the constructional design of flood and coastal protection structures is common practise in coastal engineering.

To analyse wave conditions in the South Western Baltic Sea, wave information within this area are needed. There are several methods available to obtain this information like e.g. wave measurements, simple parametric approaches, statistical methods and numerical wave simulations. For the investigations, presented in this paper, a hybrid approach has been established, which consists on the one hand side of statistical methods and on the other hand side of numerical wave simulations to calculate wave information. The approach uses wind data from numerical climate simulations as input data.

In this study, changes in wind conditions are applied from the regional climate model CCLM (Rockel et al. 2008). Since the wave conditions were derived for locations in the Baltic Sea near the $10 \mathrm{~m}$ depth contour line ca. $1 \mathrm{~km}$ off the coast (quasi deep water conditions) the local sea level rise could be neglected. Furthermore two of the future emission scenarios A1B and B1 compiled from the Special Report On Emissions Scenarios (SRES) have been taken into account (Nakićenović et al. 2000).

\section{GENRAL APPROACH}

\section{Used Climate Data}

The regional climate model CCLM provides dynamical downscaled wind conditions from the coupled atmospheric global climate/sea-ice ocean model ECHAM5/MPI-OM as forcing model. There have been carried out different CCLM model runs (Lautenschlager et al. 2009), covering the $20^{\text {th }}$ century (1960-2000) and the $21^{\text {st }}$ century (2001-2100) as compiled in Table 1.

As shown in Table 1, there are 3 independent realisations available for the climate of the $20^{\text {th }}$ century, each forced with observed anthropogenic forcing and started 25 years apart from each other (C20_1 to C20_3). For the modelling of the future climate only the first two of the climate model runs for the $20^{\text {th }}$ century were continued and forced by the SRES scenarios A1B (global economic) and B1 (global environmental), resulting in 4 independent realisations. The realisations for the past and the future have been combined to 4 transient time series of wind conditions covering a period from 19602100 .

\footnotetext{
${ }^{1}$ Institute of Geotechnics and Coastal Engineering, University of Rostock, Justus-von-Liebig-Weg 6, Rostock, 18059, Germany

${ }^{2}$ Institute of River and Coastal Engineering, Hamburg University of Technology, Denickestr. 22, Hamburg, 21073, Germany
} 


\begin{tabular}{|l|l|l|l|}
\hline \multicolumn{2}{|c|}{ Table 1. CCLM model runs (remark: ' $x$ ' denotes no experiment). } \\
\hline $\begin{array}{l}20^{\text {th }} \text { century } \\
\text { observed } \\
\text { anthropogenic } \\
\text { forcing }\end{array}$ & $\begin{array}{l}21^{\text {st }} \text { century } \\
\text { forced by } \\
\text { emission } \\
\text { scenario A1B }\end{array}$ & $\begin{array}{l}21^{\text {st }} \text { century } \\
\text { forced by } \\
\text { emission } \\
\text { scenario B1 }\end{array}$ & $\begin{array}{l}\text { transient time } \\
\text { series of wind } \\
\text { parameter }\end{array}$ \\
\hline C20_1 & A1B_1 & X & C20_1+A1B_1 \\
C20_1 & X & B1_1 & C20_1+B1_1 \\
C20_2 & A1B_2 & X & C20_2+A1B_2 \\
C20_2 & X & B1_2 & C20_2+B1_2 \\
\hline
\end{tabular}

\section{Hybrid Approach}

For the statistical assessment of changes of wave conditions, induced by regional climate change, gapless long-term time series of wave parameters (e.g. for a minimum time period of 30 years) are needed. Long-term time series of wave parameters can be obtained by using different wave prediction techniques (e.g. calculation with the help of a numerical model, statistical or empirical approach).

For the derivation of long-term time series of wave data a hybrid approach was developed that calculates the wave data with the help of wind-wave-correlations and numerical simulations based on wind data from different runs of the regional climate model CCLM (cp. Table 1).

\section{Wind-Wave-Correlations}

On the basis of available synchronized local field data for wind and waves (e.g. data from wind gauge measurements and directional wave buoys) wind-wave-correlations have been derived for different locations at the German Baltic Sea Coast.

Figure 1 shows the three locations which have been used in this study: Warnemünde (cp. Figure 1 right), Travemünde (Bay of Lübeck, cp. Figure 1 bottom) and Westermarkelsdorf (Island of Fehmarn/Bay of Kiel, cp. Figure 1 top).

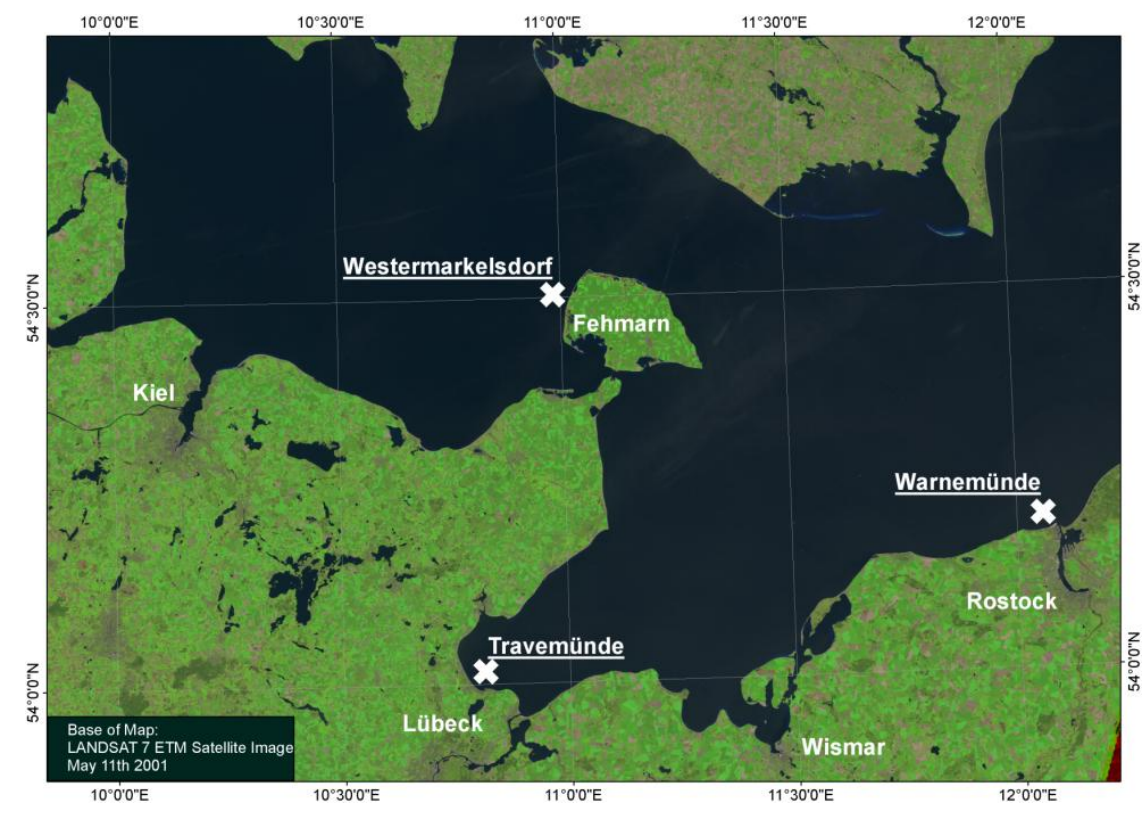

Figure 1. Study area and locations used for the investigations.

With the help of statistical correlation methods the nonlinear relation between the wind field and the resulting wave conditions can be obtained for a certain area of interest (Fröhle 2000, Fröhle \& Fittschen 1999), where field data are available. In this study we calculate the wave parameters significant wave heights $H_{m 0}$, mean wave directions $\Theta_{m}$ and mean wave periods $T_{m 02}$ from mean wind velocities $\mathrm{U}_{10}$ and mean wind directions $\Theta_{\mathrm{w}}$.

Figure 2 shows exemplarily the good agreement between calculated and measured wave heights, periods and directions at the location Warnemünde. The mean absolute deviations between the calculated and observed wave heights are below $10 \mathrm{~cm}$ for each of the selected locations. 

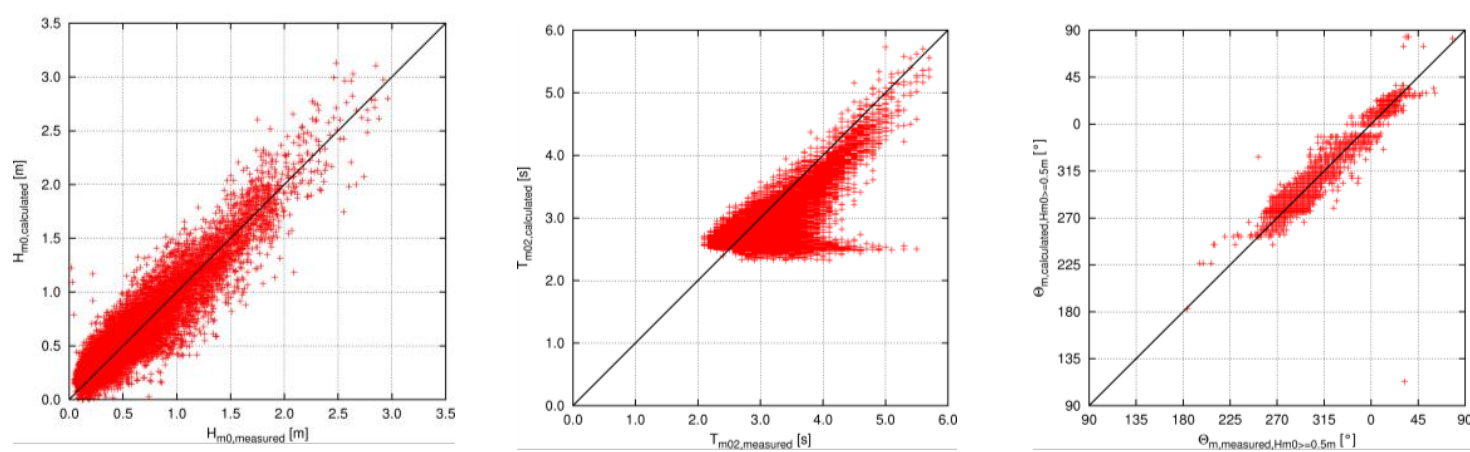

Figure 2. Calculated and observed wave heights (left) wave periods (middle) and wave directions for significant wave heights $>0.5 \mathrm{~m}$ (right), location Warnemünde.

The statistical correlations between the wind velocities and the resulting wave heights in each directional class are connected to a certain error margin. Based on a sensitivity analysis of different cut off wind speeds, a cut off criteria for maximum wind velocities has been applied for a 5\% error margin (Equation 1).

$$
U_{\text {cut }}=1.16 U_{\text {max,correlation }}
$$

If the wind data used for the calculation of the past and future wave conditions are exceeding the maximum wind velocities used for the derivation of the wind-wave-correlations, the calculated wave heights are becoming unreliable and cannot be used for the statistical assessment of extreme wave heights.

In this case the wave parameters are calculated with the help of stationary numerical simulations using SWAN (Booij et al. 1999) instead of calculating them from wind-wave-correlations. The numerical simulations are performed at a mean sea level and the resolution of $\Delta U_{10}=1 \mathrm{~m} / \mathrm{s}$ for the wind velocities and $\Delta \Theta_{\mathrm{w}}=10^{\circ}$ for the wind directions as boundary conditions. Figure 3 is showing exemplarily the calculated significant wave heights and the mean wave directions within the example area.

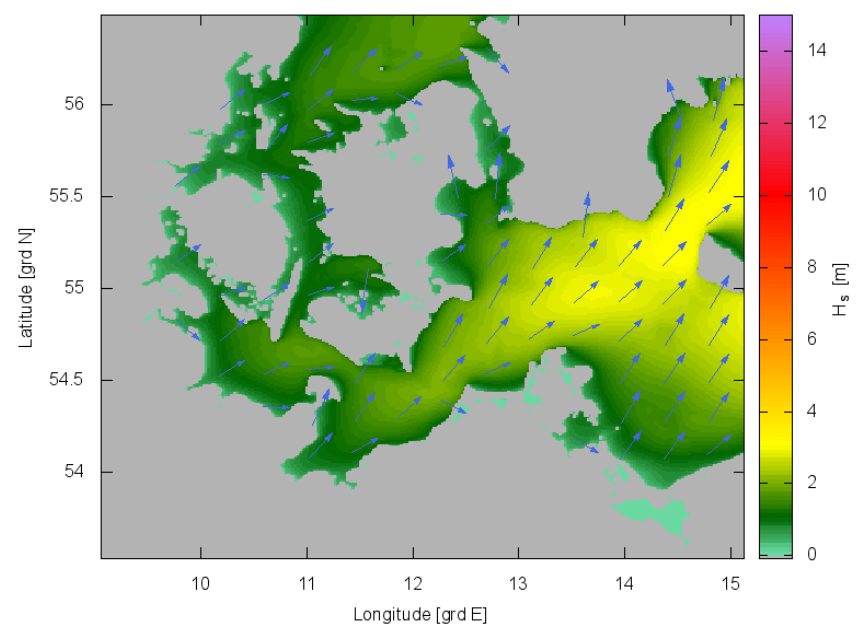

Figure 3. Calculated wave heights and wave directions (arrows) within the study area.

\section{Evaluation Periods}

From a statistical point of view, climate change is defined as the change of "the statistical description in terms of the mean and variability of relevant quantities" of the climate state over a specific period of time; as mentioned in Appendix I, $4^{\text {th }}$ Assessment Report from IPCC 2007. For the assessment of climate change and climate change inducted processes, the World Meteorological Organization (WMO) recommends a time period of 30 years. 


\section{RESULTS}

\section{Change of future wind conditions}

The North German Climate Bureau compiles results on possible future changes of wind conditions for the area of the German Baltic Sea Coast (Meinke et al. 2010). The analyses were carried out on the basis of data from multi-ensemble climate simulations (e.g. from the CERA climate data archive) using different global climate models (e.g. ECHAM5/MPI-OM, ECHAM4/OPYC3 and HadAM3H), regional climate models (CCLM, REMO, RCAO) and SRES scenarios (A1B, B1, B2 and A2).

The results are indicating an increase of the mean wind velocity, as area mean value for the German Baltic Sea coast, up to $+4 \%$ to the end of the $21^{\text {st }}$ century compared to actual conditions. Further increases of the storm intensity (maximum wind speed) up to $+4 \%$ and of the number of days with storm conditions (Bft. >8) up to +4.6 days were found, while the number of days with no wind decreases down to -1.3 days. Another outcome of the analyses is that in the future more westerly winds can occur (increases between $+7 \%$ and $+13 \%$ have been found).

The increase of the mean and maximum wind velocities on the one hand side and the change of the wind directions to more westerly winds on the other hand side can have significant effects on the change of extreme events, as we illustrate in the next section.

\section{Change of future extreme wave heights}

For the statistical assessment of the change of extreme wave heights we analysed 4 transient longterm time series of wave parameters, which were calculated on the basis of the 4 transient time series of wind conditions (cp. Table 1) covering a total time period from 1960-2100.

In a first step samples of wave heights were selected by using annual maximum significant wave heights for time periods of 40 years based on each transient time series of wave data. After the selection of the samples different extreme value distribution functions (Weibull, log-normal, GEV and Gumbel) were fitted to the data using the maximum-likelihood estimation. The log-normal function showed the best fitting and was chosen for further calculations. Finally extreme wave heights over time periods of 40 years were calculated for each year within the time period 2001-2100 on the basis of the log-normal function and for a given return level. The return level of 200 years was chosen, though it is used as a parameter for the design of coastal and flood-protection structures along the German Baltic Sea Coast.

Figure 4 shows exemplarily the chosen log-normal function (dashed line) after fitting to the samples for the time series of wave heights for the CCLM model run C20_1 and a time period 19612000. For a given return level of 200 years a significant wave height of $4.65 \mathrm{~m}$ is concluded (cp. Figure 4).

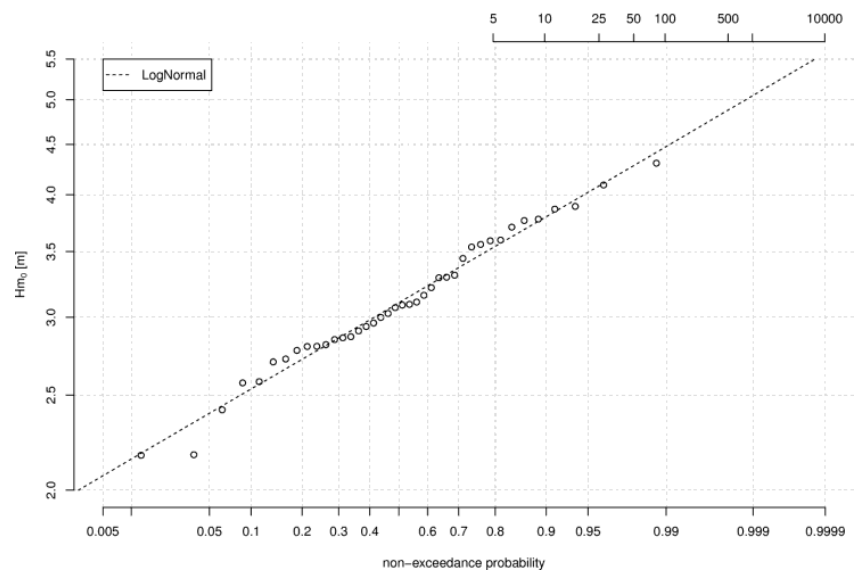

Figure 4. Annual maximum wave heights for the CCLM model run C20_1 (1961-2000) plotted on log-normal paper, plotting position by HAZEN, location Warnemünde.

Example results for the change of the calculated extreme wave heights for the period 2001-2100 are shown in Figure 5. 

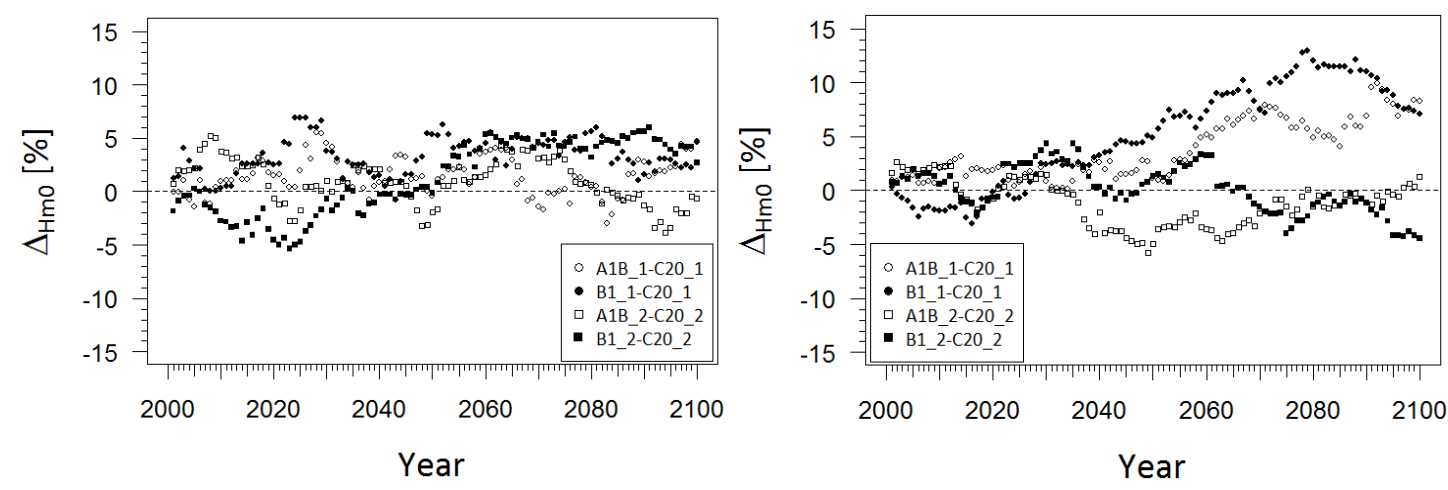

Figure 5. Change of extreme wave heights over time periods of 40 years for different model runs of the climate change scenarios A1B and B1 compared to the

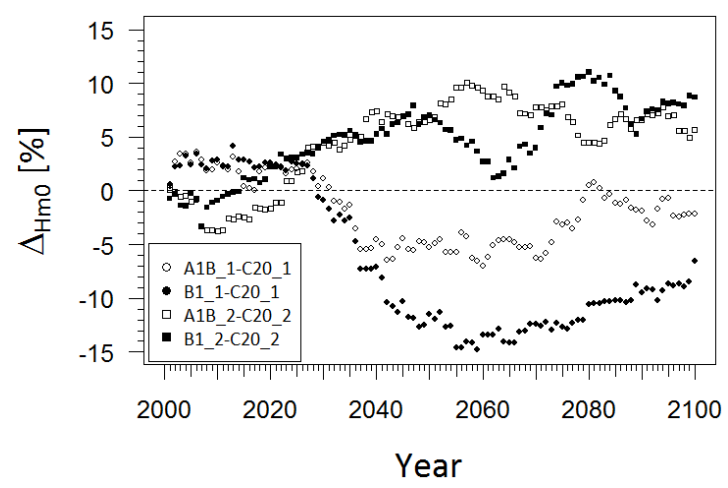
control period (1961-2000), near Warnemünde (top left), Travemünde (top right) and Westermarkelsdorf (bottom left).

From the beginning of the year 2040, the change of the extreme wave heights at the location Warnemünde (cp. Figure 5 top left) shows in general a slight increasing trend with a maximum increase of up to $+5 \%$, except for one scenario run (C20_2+A1B_2) which shows a maximum decrease of down to $-5 \%$.

Near Travemünde (cp. Figure 5 top right) the extreme wave heights for each two of four scenarios runs can increase up to $+14 \%$, but also decrease down to $-5 \%$. The same tendency can be found for the extreme wave heights near the location of Westermarkelsdorf (cp. Figure 5 bottom left), where each two of four scenarios runs are showing, that both an increase of up to $+10 \%$, but also an decrease of down to $-14 \%$ is possible at this location.

To conclude, the statistical analyse of extreme wave heights shows no clear tendency towards a general increase or decrease of extreme wave heights for the future. The results spread widely depending on the location, the chosen statistical parameters for the extreme value analysis (like e.g. the extreme value function, return level etc.), the scenario run and finally also the time period of the projection.

One can also connect the change of an extreme wave height, to the change of the return level for a given extreme event. The difference between both analyses is, that in the first case the return level is kept constant and the extreme wave height changes and that in the second case the extreme wave height is kept constant while the return level changes. This is exemplarily shown for selected wave heights within time periods of 30 years in Figure 6.

For a given return level of 200 years an extreme wave height of $\mathrm{H}_{\mathrm{m} 0}=4.66 \mathrm{~m}$ is calculated on the basis of the log-normal function for the model run C20_1 and the time period 1971-2000 (cp. Figure 6 left). When this wave height is kept constant and we use the fitted log-normal function of the scenario A1B_1 and the time period 2071-2100 for calculating the return level, the return level then decreases from 200 years to a return level of 40 years (cp. Figure 6 right). 

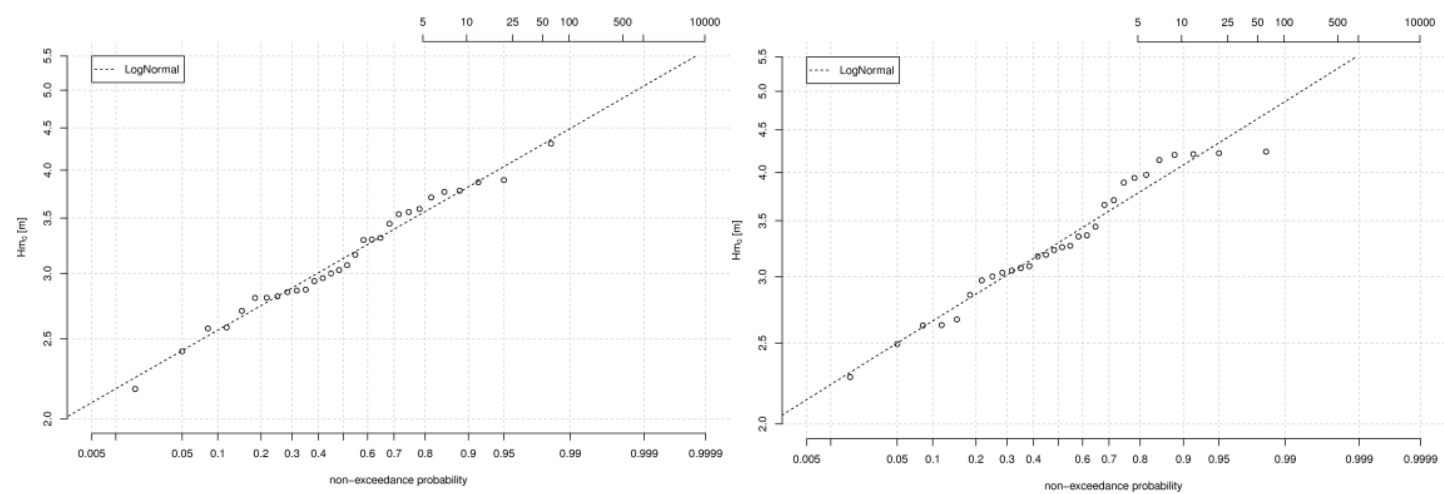

Figure 6. Annual maximum wave heights for CCLM model run C20 1 (1971-2000, left) and A1B 1 (2071-2100, right) plotted on log-normal paper, plotting position by HAZEN, location Warnemünde.

\section{CONCLUSION}

Analyses of future changes of extreme wave heights using regional climate change scenarios can provide a basis for the development of future coastal and flood protection structures. In this study a hybrid approach for the determination of wave parameters was introduced, that consists of wind-wavecorrelations and stationary numerical simulations.

With the help of this approach long-term time series (1960-2100) of wave parameters were derived on the basis of wind data from the regional climate model CCLM using two different SRES scenarios $\mathrm{A} 1 \mathrm{~B}$ and B1. The compiled time series of wave parameters were then analysed by comparing calculated extreme wave heights (return level of 200 years) for the future to actual conditions.

At one of the investigated locations (Warnemünde) we found a slight increasing trend for 3 of 4 time series of wave parameters showing increases of the extreme wave heights up to $+7 \%$ compared to actual conditions. At the other locations both increases and decreases of extreme wave heights up to $+14 \%$ respectively down to $-14 \%$ were examined.

The changes of extreme wave heights are depending on e.g. the location, the chosen extreme value function and the return level used for the analyses, but also on the scenario run and projection period.

\section{USED CLIMATE MODEL ABBREVATIONS}

CCLM COSMO-Climate Local Model

CERA Climate and Environmental Retrieving and Archiving

ECHAM5/ coupled general circulation sea-ice/ocean model developed at the Max Planck

MPI-OM Institute for Meteorology, Hamburg (MPIM)

HadAM3H Hadley Centre Atmosphere Global Climate Model

OPYC3 Ocean General Circulation Model developed in cooperation of MPIM/DKRZ

(German Climate Computing Centre)

RCAO Rossby Centre Coupled Atmosphere-Baltic Sea Regional Climate Model

REMO Regional Climate Modelling

\section{USED CLIMATE DATA}

Lautenschlager, M., Keuler, K., Wunram, C., Keup-Thiel, E., Schubert, M., Will, A., Rockel, B. and Boehm, U. 2009. Climate Simulation with CLM. Climate of the 20th Century run no.1-3, Scenario A1B run no.1-2, Scenario B1 run no.1-2, Data Stream 3: European region MPI-M/MaD. World Data Centre for Climate.

\section{ACKNOWLEDGMENTS}

The results described in the paper were conducted within the research project RADOST (Regional Adaptation Strategies for the German Baltic Sea Coast, grant nr. 01LR0807F) as part of the research priority KLIMZUG (Managing Climate Change in Regions for the Future) funded by the German Ministry of Education and Research (BMBF). 


\section{REFERENCES}

Booij, N., Ris, R.C. and Holthuijsen, L.H. 1999. A third-generation wave model for coastal regions. Part I - Model description and validation. Journal of Geophysical Research, 104, C4, 7649-7666.

Dreier, N., Schlamkow, C., Fröhle, P. \& Salecker, D. 2012. Future wave conditions at the German Baltic Sea Coast on the basis of wind-wave-correlations and regional climate change scenarios. In: Book of Abstracts - PIANC-COPEDEC VIII: Eighth International Conference on Coastal and Port Engineering in Developing Countries, IIT Madras, Chennai, India, 20-24 February 2012.

Fröhle, P., Fittschen T. 1999. Assessment of short-term directional wave measurements with respect to long-term statistical evaluations. Proc. 5th Int. Conf. on Coastal and Port Engineering in Developing Countries (COPEDEC V), Cape Town, South Africa, 1005-1016.

Fröhle, P. 2000. Messung und statistische Analyse von Seegang als Eingangsgröße für den Entwurf und die Bemessung von Bauwerken des Küstenwasserbaus (Measurement and statistical analysis of sea state as a basis for design of coastal engineering constructions), Rostocker Berichte aus dem Fachbereich Bauingenieurwesen, Heft 2, Rostock, 2000 (in German language).

IPCC, 2007. Climate Change 2007. Impacts, Adaptation and Vulnerability. Contribution of Working Group II to the Fourth Assessment Report of the Intergovernmental Panel on Climate Change, M.L. Parry, O.F. Canziani, J.P. Palutikof, P.J. van der Linden and C.E. Hanson, Eds., Cambridge University Press, Cambridge, UK, 976pp.

Meinke, I., Gerstner, E., von Storch, H., Marx, A., Schipper, H., Kottmeier, C., Treffeisen, R. and Lemke, P. 2010. Regionaler Klimaatlas Deutschland der Helmholtz-Gemeinschaft informiert im Internet über möglichen künftigen Klimawandel. Mitteilungen DMG 02/2010, 5-7, ISSN 01778501.

Nakićenović, N., Alcamo, J., Davis, G., de Vries, B., Fenhann, J., Gaffin, S., Gregory, K., Grübler, A., Jung, T.Y., Kram, T., La Rovere, E.L., Michaelis, L., Mori, S., Morita, T., Pepper, W., Pitcher, H., Price, L., Raihi, K., Roehrl, A., Rogner, H.-H., Sankovski, A., Schlesinger, M., Shukla, P., Smith, S., Swart, R., van Rooijen, S., Victor, N. and Dadi, Z. 2000. Emissions Scenarios. A Special Report of Working Group III of the Intergovernmental Panel on Climate Change. Cambridge University Press, Cambridge and New York, 599 pp.

Rockel, B., Will, A. and Hense, A. (eds.) 2008. Special Issue: Regional climate modelling with COSMO-CLM (CCLM). Meteorologische Zeitschrift, Vol. 17. 